Timothy O’Leary

\title{
Rating existing housing stock for energy performance - development of an Australian national scheme
}

\author{
Timothy O'Leary $^{1}$, Martin Belusko ${ }^{2}$ and Frank Bruno ${ }^{2}$ \\ (1) School of Natural and Built Environments(NBE), University of South Australia (UNISA), City East \\ Campus, Adelaide, SA 5000, Australia. tim.oleary@unisa.edu.au \\ (2) The Barbara Hardy Institute, School of Engineering , University of South Australia, Mawson Lakes \\ Campus, Adelaide, Australia.
}

DOI: http://dx.doi.org/10.5130/ssep2016.518

\begin{abstract}
The mandatory disclosure of residential building energy, greenhouse and water performance has been a key goal expressed in Australian government building energy and carbon emission reduction targets. A major issue for the Australian real estate industry since a proposed scheme was mooted in 2011 is what will mandatory disclosure look like?
\end{abstract}

This paper provides an analysis of home energy efficiency rating and the current Residential Building Mandatory Disclosure (RBMD) landscape in Australia at both the Commonwealth and State/Territory level. The release of a Regulatory Impact Statement (RIS) including an assessment of the costs and benefits of various options for a national scheme provides a measure of likely regulation and practices around house sale and lease transactions.

Some five years on since the introduction of more stringent energy efficiency performance regulations for new housing and the declaration by an Australian federal government that states and territories adopt energy performance disclosure mechanisms for older houses at point of sale or lease, issues with implementation and the perception of stakeholders and the tools that may be employed are investigated as are wider energy efficiency and sustainability issues to do with the nation's housing stock.

Keywords: mandatory disclosure, home energy efficiency 


\section{Introduction}

In Australia, the regulation of energy efficiency of buildings is covered by a range of Commonwealth, State and Territory agencies. In 2009 specific measures to increase energy efficiency of buildings were set out in a Council of Australian Governments (COAG 2009) agreement with measures specifically for residential class buildings proposing:

- the phase-in of mandatory disclosure of residential building energy, greenhouse and water performance at the time of sale or lease, commencing with energy efficiency by 2011;

- an increase in energy efficiency requirements for new residential buildings to six stars, or equivalent, nationally in the 2010 update of the Building Code of Australia with full implementation by all states by 2011 .

The latter of the measures outlined above has now been implemented in all Australian states though with some variations, such as in Queensland where the 'six star' measure can be achieved with significant concessions for utilising an outdoor living space as part of the house design. The first of the two measures listed above has not been implemented to date though it should be noted that in the area of the Australian Capital Territory (ACT) which predominantly relates to housing within and around the national capital Canberra, a system of house energy performance disclosure at point of sale has been in place for well over a decade. The ACT stands alone as having implemented a system of residential mandatory disclosure, whereas other states have grappled with implementation of such a scheme for their older existing housing stock.

Understanding user behaviour and the occupancy profile of any housing unit irrespective of its construction form is fundamental to an assessment of housing energy efficiency. In some studies the existing housing stock is presented as a more fruitful area of energy demand reduction than new housing, as ratings using the current crop of tools for measuring energy efficiency show existing homes can be well below the new 6 star standard and can be as low as $1-2$ stars. The Moreland Foundation (2011) in a recent study of older housing in Victoria found the average energy rating of the existing houses was 1.3 stars, indicating just how much less efficient typical existing houses are compared to newly built houses. The sample of houses was small but represented a spread of ages typical of inner city homes built in the period (1900-1980) Some houses had no ceiling insulation, poor window performance and had high level of air infiltration due to inadequate draught proofing and sealing.

This paper presents analysis of an Australian Federal Government initiative around various options for a nationwide Residential Building Mandatory Disclosure (RBMD) scheme. It provides an examination of a Regulatory Impact Statement (RIS) around the proposals together with analysis of some key housing industry stakeholder's points of view through public submissions around these government proposals. This principal aim of this research paper is then to promote a greater awareness amongst property professional particularly in the residential sphere in Australia of RBMD proposals and housing energy efficiency labelling. It provides an analytical framework around both the technical considerations of house energy rating and policy goals for the possible future implementation nationally of a mandatory disclosure scheme for housing energy efficiency in Australia.

\section{Australian House energy rating schemes (HERs) and energy efficiency initiatives}

According to Reardon (2005) rating tools for Australian households that have been developed to fall into two broad types, although some combine both approaches.

- "Those that predict performance at the design stage, such as house energy rating tools."

- "Those that measure the actual performance of the building, including behaviour and appliances."

This distinction between the two types is important because it defines how the tools can be used. Predictive tools that have standardised user profiles may be used for regulatory purposes by providing a comparison between buildings that assumes similar behaviour patterns. These tools attempt to predict the future performance of new or existing buildings by eliminating the influence of current user behaviour. Tools that provide feedback on how people are actually using a given building are more valuable for examining how occupant behaviour might be changed to reduce a building's impact on the environment, but these tools cannot be readily used for 
regulatory purposes. These tools are particularly useful at tracking improvements to the environmental management of a building. Aspects of building environmental performance that can be rated include:

- Performance of individual appliances and fixtures such as fridges, shower heads, gas heaters etc.

- Performance of individual building elements such as windows.

- Performance of a combination of elements such as the building envelope.

- Performance of a whole building

Current regulation for new housing in Australia allows the use of one of three separate software tools to demonstrate compliance with mandated minimum performance targets. The energy rating of new single dwellings can be determined by computer software provided that it complies with the relevant Australian Building Codes Board (ABCB) Protocol for House Energy Rating Software. Regulatory House Energy Rating Schemes (HERS) in Australia such as the Nationwide House Energy Rating Scheme (NatHERS) have traditionally only assessed the thermal performance of residential buildings, that is the anticipated annual heating and cooling energy demand. HERS tools calculate the heat energy gains and losses associated with the design of the building in a particular location, and determine how much artificial heating and cooling may be required to maintain human thermal comfort. HERS software accredited under NatHERS can be used to assess compliance with the Building Code of Australia (BCA) and other regulations. The rating using a $0-10$ stars band is a graded adjustment taking into account house size and location as climate influences heating and cooling loads and the size of a house floor area will affect the heat transmission for a given wall area.

The aforementioned Regulatory HERS in Australia do not include the energy use of appliances or the embodied energy of building materials, although work is underway to broaden Australian HERS tools to cover other energy impacts such as lighting, hot water, and major fixed appliances. This is work incorporated by CSIRO (2010) in its release of the beyond $2^{\text {nd }}$ generation tool Accurate Sustainability, now in version 2.3.313. New South Wales building regulatory processes use a variation of NatHERS called the Building Sustainability Index (BASIX) which is an online, predictive assessment tool. The designer of a house or unit enters data about the dwelling into the BASIX tool. Requested information includes 'site location, house size, type of building materials, and fittings for hot water, cooling and heating' (NSW Department of Planning, 2006). After analysing this data, the BASIX tool provides a score for the design against its water, thermal and energy performance.

The Australian Capital Territory (ACT) acting independently of other states and territories first introduced a RBMD scheme in 1999, later revised under the Civil Law (Sale of Residential Property) Act 2003. The scheme which seeks disclosure of the buildings energy efficiency operates independently from the Australia Building Code and the ACT state planning and building approvals processes. Initially when introduced the star rating scale was a $1-6$ stars scale due to the use of the earlier developed $1^{\text {st }}$ generation assessment NATHERS based software tools outlined above, however since the introduction of $2^{\text {nd }}$ generation thermal assessment modelling it now uses the $1-10$ star model corresponding to the current NatHERS starbands. All ACT ratings are under one NatHERS climate zone, being climate zone no. 24 Canberra, ACT. Essentially in the Australian Capital Territory if as a vendor you are about to sell a dwelling you occupy or one that is occupied or rented to tenants, you need to disclose to prospective purchasers the current level of energy performance of the dwelling. Real Estate Agents, vendors and energy assessors will need to ensure that advertised EERs comply with the Civil Law (Sale of Residential Property) Act however the direct responsibility is with the vendor for the provision of the EER certificate. Section 20A of the Residential Sales Act authorises the ACT Planning and Land Authority (ACTPLA) to make guidelines for the preparation of EER statements (the Guidelines). As a vendor under the ACT EER scheme you need to:

1. include the EER value in all sales advertising of the property; for example, EER 3

2. provide a copy of the EER Statement to the purchaser

3. ensure that the EER Statement forms part of the contract for sale.

The Queensland government in 2010 briefly introduced a somewhat more holistic however less technically rigorous sustainability declaration method of disclosing information on a properties energy systems. The sustainability declaration was a compulsory checklist that had to be completed by the seller (vendor) when selling a house, townhouse or unit. The checklist was designed to identify the property's environmental and social sustainability features in these key areas: energy, water, safety and access. The declaration was designed to be completed by the property owner or a delegated individual. If an owner was unable to complete the form, they could seek help from another person to complete it on their behalf as long as the owner signed it. To comply with the scheme a copy of the completed sustainability declaration was required to be conspicuously 
displayed whenever a home was open for inspection by the seller, such as at an open house. The Queensland scheme however was scrapped in July 2012 with no replacement currently under consideration. Research by Bryant \& Eves, (2012) in a survey of real estate agents operating under the Queensland sustainability declaration model found that whilst a high level of compliance with the provision of declaration existed there was widespread disengagement with the sustainability declaration process from both sellers and buyers. In fact the survey they undertook indicated that a massive $98 \%$ of buyers do not ask for a copy of the sustainability declaration at any time during the sales process. In Queensland a secondary market developed in online ' sustainability declaration 'providers who for a fee as low as $\$ 100$ would help the owner generate the necessary declaration based on self- assessment of their properties features in the 4 key areas.

In other states in Australia no mandatory disclosure scheme currently exists for sales of existing homes however a property's energy supply profile can be part of the requirements to show vendor information. An example of this requirement is in South Australia under the relevant real estate sales legislation through the SA Office of Consumer Affairs (2010) where the following question is required to be addressed in some fashion; " How energy efficient is the home, including appliances and lighting? What energy sources (e.g. electricity, gas) are available" This is part of the Form R3 the standard form for statutory disclosures used in real estate transactions in South Australia. There have been recent moves by the Victorian Government to develop a web based Residential Efficiency scorecard assessment tool that uses features of HERs type assessment, that would require a user to register and be appropriately trained in house energy assessment and that would provide advice to prospective house purchasers of the cost and benefits of improving the energy performance of the property in question. Some background details to the scheme were announced at a Victorian government energy summit held in August 2015 and according to the Fifth Estate (2015) the move shows hopefully the Victorian government was seeing there is consensus building around mandatory disclosure and minimum energy standards across the residential sector. It is anticipated in 2016 that further particulars of this scheme will be released.

\section{Energy bill data and occupancy factors - avoiding the problem of rating the user and not the building}

Irrespective of any mandatory disclosure mechanisms, Australians can voluntarily self-assess their homes energy efficiency under such freely available assessment tools as the NABERS home energy tool which uses historical billed energy data to rate a houses energy performance (see figure 1 below).

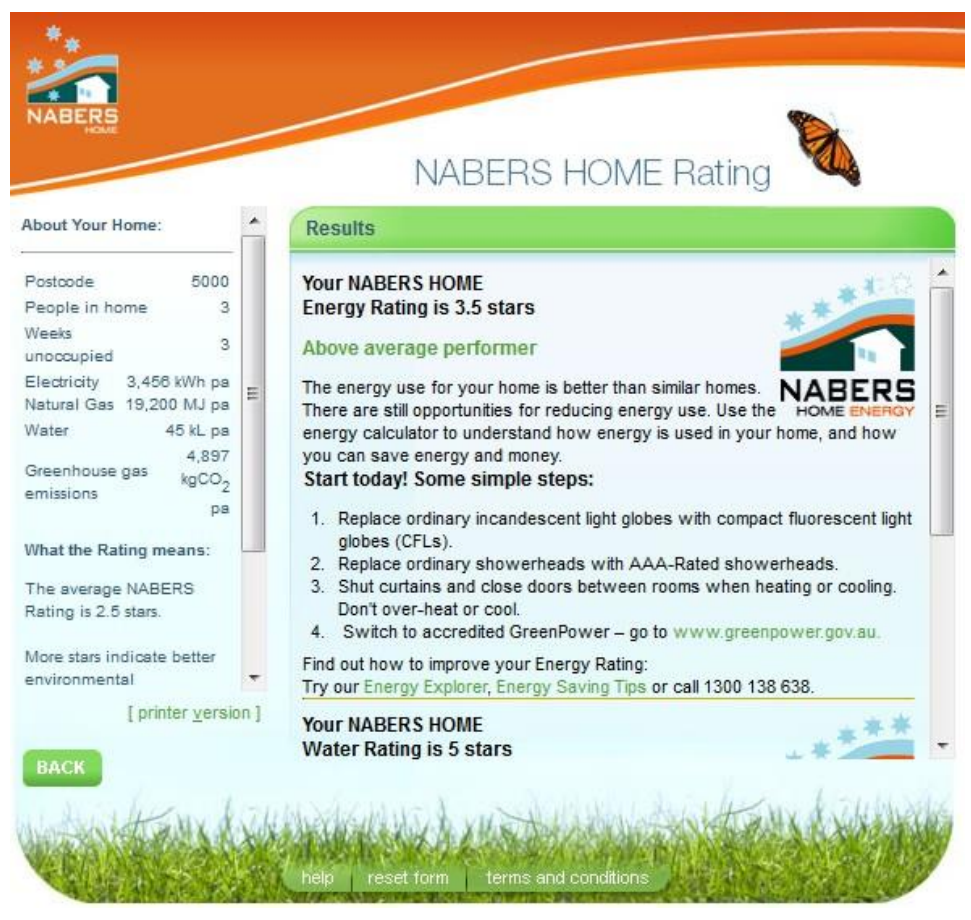

Figure 1:

NABERS Home rating online assessment - source www.nabers.org.au 
According to NABERS (2015) to rate any home for energy efficiency requires the last 12 consecutive months of energy bills. Energy use is compared to the average home and a rating scale using 1(poor) to 5(excellent) is assigned to the house adjusted to account for how many people live in the home and how many weeks each year your home is occupied. The tool also provides a rating for house water consumption based on water bills. This role of data from energy bills also used in some overseas schemes has been investigated in South Australia in a report by Sustainable Focus (2010) commissioned for the government in anticipation of adoption of a RBMD scheme in Australia. This report proposes that billing data be used as a check against whatever other tool(s) are selected to determine household energy performance and in the opinion of the report's authors the question of a role for energy billing data in Mandatory Disclosure appears to be missing from the current national debate or proposed models of RBMD. In their view it is critical that historical energy consumption information be provided that is useful to the new owner/lessee and/or the vendor/lessor. This information will be useful if it can enable the comparison of different dwellings likely energy performance and provide practical guidance on how to improve energy performance. The information must also be usable by real estate agents, so it should highlight both good and bad features, and possibly flag options for improvement that might be feasible in the sale process.

Billing data however, is not found to be a reliable predictor of future energy performance in a recent study by O'Leary et al. (2015). Observations from their case study of energy rated houses also in South Australia using detailed energy monitoring and bill data showed marked variation in individual household energy use patterns for houses of similar star ratings. The mandated roll out of smart meter technology in Victoria ( Smartmeters 2015) in the past four years seen as initially problematic in part due to consumer consultation and information issues has seen metering utilised more as an electricity demand management tool than an energy performance disclosure mechanism. Fundamentally the user behaviour issue remains a big concern for any disclosure scheme using consumption data, as the research suggests strongly that human behaviour challenges building performance evaluations and that recognition of the diversity of inhabitants and comfort scenarios is required when considering regulation and standards. Housing occupants can use three or more times as much energy for heating as their neighbour, while living in exactly the same type of home (Gram-Hanssen, 2010). This suggests that even if the building fabric is robust and well insulated with suitable thermal mass, and the home has an efficient energy source, it will still be the inhabitant who ultimately determines how energy efficient a home will be. Even if the amount of energy consumed by the building for heating and cooling space is low, occupants will still be free to use as much energy as they like for appliances and hot water systems.

\section{Proposed national model of a residential mandatory disclosure scheme}

July 2011 saw the release of a consultation Regulation Impact Statement (RIS) for mandatory disclosure of residential building energy, greenhouse and water performance with a following consultation period for industry stakeholders, groups and individuals to comment on proposals. The latter half of 2011 saw the policy development process initiated by the COAG declaration of 2009 whereby measures or various options were modelled for regulatory implementation, consumer and market acceptance as well as national and state level cost benefit analyses. The options (Allen Group 2011) proposed are broadly classified as;

- regulatory options ( choice of options, nos $1-4$ )

- $\quad$ non-regulatory options ( option 5)

- $\quad$ assessment opt-out ( option 6 )

- $\quad$ base case - maintain current approach

The proposed options ( see table 1 below) would apply to the sale and/or lease of all types of residential buildings (separate houses, semi-detached houses, flats, units and apartments), with the possible exception of housing associated with shops and offices, mobile homes, hospices and aged care accommodation as well as social and remote housing. The preliminary findings of the RIS study based on market information indicates that there are regulatory and non-regulatory options for intervention where the community would be better off with intervention than without it. That is, there are a number of options where on the basis of the modelling undertaken the benefits exceed the costs. The question of costs and benefits is contested. Residential Building Mandatory Disclosure is characterised by a mandated aspect, which drives the costs, and a voluntary aspect, which drives the benefits. Given this fact, the estimated costs are fairly certain, whereas estimated benefits are inherently uncertain. In particular, the benefits are largely driven by the assumed voluntary investment response (or uptake rate). There is not enough information to measure the level of uncertainty around the assumed uptake rate, but it is likely to be large. 


\begin{tabular}{|c|c|c|}
\hline Option & Advantages & Disadvantages \\
\hline 1. Full Themal Assessment & $\begin{array}{l}\text { - Site-specific } \\
\text { - Most accurate } \\
\text { - Based on NathERS thermal performance } \\
\text { - Requires homeowner to engage with assessor which enables the } \\
\text { - transfer of information } \\
\text { - Recommendations tailored to homeowners specific needs }\end{array}$ & $\begin{array}{l}\text { - Requires full house plans andlor significant assumptions } \\
\text { that increases the costs and may reduce effectiveness of } \\
\text { recommendations } \\
\text { - May create additional confusion for homeowners and the } \\
\text { marketplace about NathERS and the difference between } \\
\text { NatHERS and RBMD }\end{array}$ \\
\hline 2. Simplified Thermal Assessment & $\begin{array}{l}\text { - Site-specific } \\
\text { - Focuses on the 'built-in' capacity of a house to achieve sustainability } \\
\text { outcomes, rather than the 'botted-on' features such as water tanks etc } \\
\text { - Currently more cost effective than option } 1 \\
\text { - Good transition option to facilitate long-term adoption of option } 1 \\
\text { - Requires homeowner to engage with assessor which enables the } \\
\text { transfer of information } \\
\text { - Recommendations tailored to homeowners specific needs } \\
\end{array}$ & $\begin{array}{l}\text { - Less accurate (than option 1) } \\
\text { - Requires a number of assumptions that reduces the site- } \\
\text { specific accuracy, and which can cause confusion }\end{array}$ \\
\hline 3. Online self assessment & $\begin{array}{l}\text { - Easy to create and track data } \\
\text { - Contains a minimum judgment of thermal performance }\end{array}$ & $\begin{array}{l}\text { - Does not require an assessor which can lead to errors and } \\
\text { requires the assessment to be overly simplistic andlor rely } \\
\text { on large assumptions } \\
\text { - Does not provide homeowners with new and tailored } \\
\text { knowledge about their property } \\
\text { - Almost impossible to provide quality assurance } \\
\text { - Will tend to focus consumers on 'bolted-on' features such } \\
\text { as water tanks, rather than those aspects which are 'built- } \\
\text { in' and reduce consumption }\end{array}$ \\
\hline 4. Self assessment checklist & $\begin{array}{l}\text { - Identifies the houses which have easy to understand sustainability } \\
\text { features (ie water tanks, solar hot water, PVs) }\end{array}$ & $\begin{array}{l}\text { - Does not provide a comparable rating } \\
\text { - Does not consider 'built-in' features of thermal } \\
\text { performance that reduce consumption } \\
\text { - Does not require an assessor which can lead to errors and } \\
\text { requires the assessment to be overly simplistic and/or rely } \\
\text { on large assumptions } \\
\text { - Does not provide homeouners with new and tailored } \\
\text { knowledge about their property } \\
\text { - Impossible to provide quality assurance } \\
\text { - Ancedotal evidence (from QLLD Sustainability Declaration) } \\
\text { indicates people prefer not to indicate the presence of } \\
\text { features }\end{array}$ \\
\hline 5. Public education campaign & - Can articulate one message clearly (ie, black balloons) & $\begin{array}{l}\text { - Cannot provide site specific information } \\
\text { - Does not provide nationally consistent and comparable } \\
\text { data } \\
\text { - No guarantee that message is heard or that action is taken }\end{array}$ \\
\hline
\end{tabular}

Table 1: SUBMISSION TO RBMD RIS; COMMENTS ON OPTIONS 1 -5 Source: Regulatory Impact Statement (RIS) Public submission by Association of Building Sustainability Assessors, September 2011

Thermal efficiency assessment as described in this papers section on HERS requires adequate and accurate knowledge of the thermal mass, insulation levels and zoning of a dwelling and this in turn is reliant on adequate and accurate knowledge of the construction materials and any thermal barriers or insulation within the wall structure. Such a high level of assessment as proposed in option 1 is arguably only feasible and cost-effective in newer homes for which current, accurately drawn floor plans exist. Option 2 provides a more simplified assessment of the thermal performance of the building shell and less detailed analysis of the components (appliances) related to energy efficiency and due to its much lower cost is modelled as the most desirable from a cost/benefit standpoint.

Not a great amount of detail is provided as to what real level of assessment is required for both the building and its components however some have pointed to the type of assessment carried out under the now defunct Commonwealth government green loans scheme which contained little information on the building elements. It must be noted that, for most existing housing, house plans either no longer exist, are not held by the current home-owner, and in the case of Councils and other regulatory authorities, have often be lost or at best archived and are thus not readily accessible so the question of whether house plans are needed is a clear 'game changer' in the scenarios of option 1 versus 2 . 
Further options proposed (listed as options 3 and 4) use a self- assessment method to achieve the desired outcomes. Whether home owners will either not perform any such assessment accurately - for the same reasons of perception of potential loss as are applicable to lessees and real estate agents, or they will simply get it wrong is a key question surrounding these options. Human nature being what it is, vendors have a vested interest in not spending any money on a property they intend to sell. Additionally, they do not have any incentive to highlight potentially price-sensitive failings of their property. For that reason, there is an argument that the provision of assessments must not be performed by vendors, lessees or real estate agents as all have a vested interest in minimising the true situation. This would be akin to allowing vendors to provide 'building construction' examinations, or 'pest examinations' such as those currently required by most lending authorities and which are paid for by purchasers.

Option 5 is a non-regulatory option, which addresses the government's objective to tackle the market failure associated with a lack of information through a public education program and publicity campaign. Under this option of voluntary uptake through public education and publicity campaigns government would conduct a public education program and publicity campaign to increase awareness of the importance of improving the energy, greenhouse and water performance for residential buildings, and the opportunities that home owners, tenants and landlords have to improve the performance of buildings. This option could adopt a voluntary checklist approach similar to that outlined in Option 4. Option 5 appears designed to some extent, take advantage of the existing trained assessors such as Green Loans and for Professional development of real estate agents under this public information approach would be of significantly less magnitude than options 1 to 4 .

Option 6, the 'opt-out' approach would appear to still require agents to receive training on the regime in order to fully inform clients of their obligations and opt-out choice. Those not wishing to have a zero rating - potentially the majority - would still need to be taken through the disclosure reporting documentation so the professional development impact would not differ greatly from options 3 and 4.

\section{National Residential mandatory disclosure --- problem identification, stakeholder perceptions and public acceptance}

The Australian RMBD regulatory impact study does state that "the market for residential buildings suffers from information problems". Specifically it states that there is a "market failure" in the housing market leading to "information asymmetry (unevenness)" with the following undesirable outcomes being observed today, it states:

- "It is difficult to distinguish between high and low quality buildings (in relation to energy, water and greenhouse performance) at the time of purchasellease"

- "Adverse selection (the market for lemons)"

- "High quality products driven out of the market"

ABSA (2011a) in its publically available submission agrees that the problem of building inefficiency is created by information asymmetry and missing information, however, they believe that in addition to these two issues, that the problem is further complicated because the market doesn't value the information, nor understand what to do with such information and that "you can't manage what you can't measure". They favour options 1 and 2 and contend that a good rating scheme should encourage innovation by providing flexible compliance paths and not be overly prescriptive. Also that it should have the capacity to benchmark higher performance and be able to measure both minimum mandated and better performance. It should integrate the use of current rating tools and allow more impact categories to be added as housing and its impact on the environment become more understood for instance the question of embodied energy.

Results from surveys commissioned by the Clean Energy Council (2011) indicate that the problem is more complex than information asymmetry, where it is stipulated that Australians it seems, want to take action to reduce their house energy demand but are prevented from doing so by lack of information and support. In their survey 95 per cent of people said they were concerned by rising energy costs and 89 per cent said they were 
willing to take action to use less energy, half knew little or nothing at all about the key aspects of their energy use. 73 per cent of respondents said they would welcome more information on how they could use less energy or use it more efficiently.

The Residential Development Council (2011) in its submission to the RIS consultation suggests that the implementation of a mandatory disclosure scheme will have a long term impact and as such it is important to get the policy right and that any scheme requiring mandatory disclosure of energy, greenhouse and water performance should "include a public education program and publicity campaign to increase consumer awareness about the importance of improving the environmental performance of all residential buildings (existing and new)" and "secure the national implementation of a single scheme with a consistent method of assessment and measurement" with a further goal to "end consumer confusion and 'star overload' in the residential sector, especially regarding energy efficiency". Red-tape and the burden of compliance and the cost of compliance is an issue raised by a number of stakeholders such as the Law Society of South Australia (2011) in its submission stating " the society's initial view is to express disappointment that the RBMD initiative should seek to impose yet another layer of compulsory disclosure upon transactions conducted throughout Australia on a daily basis."

The RBMD consultation RIS envisages that social housing would be treated somewhat differently to other residential property types under a mandatory disclosure scheme however it does not specifically identify how the treatment of social housing would differ, recommending that this should be a matter for separate analysis. Tenants in social housing, as in the market generally, are responsible for paying ongoing energy and water bills and it is envisaged that residential mandatory disclosure can provide information to tenants to foster investment in energy efficiency measures following occupation of the building. Because they are not the owners of the property (either the building envelope or the major fixed appliances), and because they tend to have lower than average incomes, there may be little capacity for such investment by social housing tenants. The social benefits to having an improved housing stock are well documented however it remains a key concern for the acceptance of a scheme to ensure methods in place for assessing energy efficiency in a social housing context avoid the risk of providing either poorly understood information or actual misinformation to tenants and low income households with undesirable consequences.

On the question of who can provide the assessments used in energy performance disclosure ABSA (2011b) estimates there are over 2000 home energy assessors trained in "2nd Generation" software and that numbers are reasonably well spread across Australia, particularly in NSW, Vic, Qld and WA but are concentrated in capital cities. Wide geographical spread is not essential as assessors receive most plans electronically and can work from anywhere. Numbers are well distributed across the three software packages available under the National Software Protocol: AccuRate, FirstRate and BERSPro. Green Gurus (2011) contend that real estate agents and property managers are at the front line in the housing sector when people are choosing to buy or rent a home and are the missing link so far in optimising the flow of information on energy and water efficient homes. They conducted a study in WA where participating agents confirmed that marketing strategies which highlight the benefits of sustainability concepts, products and their services will be paramount to increasing demand for sustainability advice. The study found that informed real estate professionals are able to identify cost savings including subsidies available for the properties they manage/sell and communicate these to their client. They have also started to include sustainability information in their marketing material to promote the green credentials of the properties they are selling.

\section{Conclusion}

Residential Building Mandatory Disclosure is a federal government initiative which although due for phased introduction in 2011 has yet to be implemented as a national scheme. The consultation RIS provides a number of specific options for a national single scheme however as borne out by state responses such schemes may be implemented in different ways across the states and territories either as some states will choose to possibly extend their existing schemes e.g. the ACT, some abandon an existing scheme such as Queensland without moving to any new scheme or as in the case of Victoria now in 2016 move to develop a new Residential Efficiency non mandatory tool. Whilst it is beyond the scope of this paper to provide very detailed critical 
analysis of each possible variation to home energy disclosure schemes and tools and examine such impacts of the macro-economic modelling of costs and benefits, the regulation impact statement released back in 2011 has provided a basis for a broad comparison of likely schemes and elicited stakeholder comment as a valuable contribution to any assessment of likely outcomes for a national scheme.

Mandatory disclosure tools that exist for new housing and regulation of standards for new housing exist both nationally and internationally however how they might be adapted for rating existing housing stock or whether it is fact desirable to use such existing tools and what the benefits are to their use is still ill-defined. There is not a great deal evident in either the regulation impact statement or policy development processes of much in the way of learning from overseas models of mandatory disclosure and it can be argued that the federated system of states and territories in Australia each controlling their own building sale and lease regulations has not assisted the implementation of a national scheme.

Whatever National or individual State(s) based model developed for residential building mandatory disclosure, it appears likely it would need to report on both the fabric of the building as well as the appliances (especially heating/cooling), because this data will influence the veracity and usefulness of the final assessment report. Options that require a full thermal assessment of the building appear the more costly however have the advantage of being tailored to specific measures that allow either the vendor or future owner to undertake cost effective improvements in performance.

Self-assessment or checklist type options requiring no independent assessment provide less accurate data on the actual energy performance and there is evidence is of un-willingness of purchasers to either engage with or understand the information that is presented. Billing data as used in some overseas schemes does not appear to be part of the options outlined in the RBMD RIS, whilst there appears to be a case that using billing data is useful as a voluntary feedback mechanism it is fundamentally flawed as a measure of building energy performance capacity due to wide variation in occupant behaviour.

\section{References}

ABSA (2011a) Residential Building Mandatory Disclosure (RBMD) Regulatory Impact Statement (RIS) submission by Association of Building Sustainability Assessors, September 2011

ABSA (2011b) Mandatory Disclosure Concept Model, Association of Building Sustainability Assessors, Sydney NSW Suite 1 Level 9, 418A Elizabeth Street, Surry Hills NSW 2010. www.absa.net.au

Allen Consulting Group, 2011, Mandatory Disclosure of Residential Building Energy, Greenhouse and Water Performance: Consultation Regulation Impact Statement, fourth draft report to the National Framework for Energy Efficiency Building Implementation Committee, March 2011.

Bryant, L \& Eves, C. 2012 Home sustainability policy and mandatory disclosure: A survey of buyer and seller participation and awareness in QLD, Property Management, Vol. 30 Iss: 1pp. 29-51

Clean Energy Council 2011 'Response to the Consultation RIS on Residential Building Mandatory Disclosure' available at www.cleanenergycouncil.org.au, September 2011

COAG, 2009 ,Council of Australian Governments, 'National Partnership Agreement on Energy Efficiency, Canberra ACT ,July 2009

CSIRO, 2010 Accurate Helping Designers achieve energy efficient homes, available at http://www.csiro.au/science/AccuRate.html, last viewed 10/10/2015 
Fifth Estate, 2015 Victorian government considering mandatory standards and disclosure for residential buildings, last viewed 12/11/2105, available at http://www.thefifthestate.com.au/politics/government/victoriangovernment-considering-mandatory-standards-and-disclosure-for-resi/76886

Gram-Hanssen, K. (2010) Residential heat comfort practices: understanding users. Building Research \& Information, 38(2), 175-186.

Green Gurus 2011, Greening the Real Estate Industry 2011, Update identifying the best way to build capacity within the real estate profession to communicate sustainability measures to sellers, buyers, landlords and tenants, Perth, WA 2011

Law Society of South Australia, 2011 Public submission to RBMD Regulation Impact Consultations, October 2011

Moreland Foundation 2010 On-Ground Assessment of the Energy Efficiency Potential of Victorian Homes Report on Pilot Study Prepared by Moreland Energy Foundation Limited for Sustainability Victoria - March 2010

NSW, Department of Planning 2006 BASIX - Boosting the market for sustainable products in NSW by the Sustainability Unit, Department of Planning.

O’Leary, T. Belusko, M., Whaley, D. \& Bruno F. 2015 Review and evaluation of using household energy data for rating of building thermal efficiency of existing buildings, Energy and Buildings Vol. 108 Dec. 2015 DOI: 10.1016/j.enbuild.2015.09.018

Reardon, C. 2005. Your home - Australia's new sustainable home design guide 2005, Department of Environment, Water, heritage and Arts DEHWA, Canberra ACT

Residential Development Council, 2011 RDC - RMBD Regulation Impact statement submission , $12^{\text {th }}$ sept 2011, Residential Development Council, division of Property Council of Australia, Exhibition St, Melbourne VIC 3000

SA Office of Consumer Affairs, 2010 , Form R3, Buyers' information notice Land and Business Sale and Conveyancing) Act 1994 section 13A

SmartMeters, 2015 Smart metering program, Installation factsheet Victorian Government available at http://www.smartmeters.vic.gov.au/_data/assets/pdf_file/0007/1176640/Smart_ meters_-_Installation.pdf

Sustainable Focus, 2010 Residential mandatory disclosure investigations - a role for billing data? Nov 2010, Report prepared for the SA Department of Transport, Energy and Infrastructure (DTEI) - Energy Division, Adelaide, South Australia

(C)2016 by the authors. This article is distributed under the terms and conditions of the Creative Commons Attribution 4.0 International License (http://creativecommons.org/licenses/by/4.0/). 